\title{
Menstrual Bleeding Patterns and Development of Ovarian Cysts in Turkish Levonorgestrel- Releasing Intrauterine System Users
}

Umit Nayki $^{1,2 *}$, Cenk Nayki ${ }^{1,2}$, Pasa Ulug ${ }^{2}$, Mehmet Kulhan ${ }^{1,2}$, Aysegul Erdonmez ${ }^{1}$, Kenan Ertopcu ${ }^{1}$ and Yusuf Yildirim ${ }^{1,2}$

${ }^{1}$ Erzincan University, School of Medicine, Department of Obstetrics and Gynecology, Erzincan, Turkey

${ }^{2}$ Tepecik Training and Research Hospital, Obstetrics and Gynecology Unit, Izmir, Turkey

\begin{abstract}
Objective: The levonorgestrel-releasing intrauterine system (LNG-IUS) is a long acting, safe, and reversible method that has a strong contraceptive effect. When using this method, menstrual bleeding disturbance and functional ovarian cysts are common. The objective of this study is to evaluate the relationship between using LNG-IUSs with the development of a functional ovarian cyst and bleeding disturbance in Turkish women

Material and methods: This is a prospective study including 273 Turkish women with regular menstrual cycles who had been administered LNG-IUS for contraception. We assessed their one-year follow-up results regarding bleeding patterns and functional ovarian cysts.

Results: Oligomenorrhea was the most commonly seen menstrual bleeding disorder, seen in $13.5 \%$ of all subjects. Oligomenorrhea occurred in the 4-6th months of using a LNG-IUS in $70.27 \%$ of the subjects. During the one-year follow-up, $28 \%$ of the subjects who were administered LNG-IUSs had ovarian cysts. While $36.36 \%$ of the ovarian cysts occurred within 4-6 months, $57.14 \%$ of them appeared between $7-12$ months.
\end{abstract}

Conclusion: During 1-year short-term follow-up of those using LNG-IUSs, approximately one thirds of the subjects developed functional ovarian cysts and $13.5 \%$ of all complained of oligomenorrhea.

Keywords: Intrauterine device; Levonorgestrel; Functional ovarian cyst; Menstrual bleeding

\section{Introduction}

The levonorgestrel-releasing intrauterine system (LNG-IUS) is used commonly for both contraceptive [1] and non-contraceptive indications such as the treatment of heavy menstrual bleeding or the prevention of endometrial hyperplasia during estrogen replacement therapy $[2,3]$. The vertical stem of this plastic T-shaped device contains $52 \mathrm{mgr}$ of levonorgestrel, which is released at a daily dose of $20 \mu \mathrm{g}$ over 5 years (q). When using an LNG-IUS, the endometrium becomes thinner, and grandular atrophy and stromal decidualization occur [4]. The response of ovaries to an LNG-IUS is directly linked to serum levels of levonogestrel. More than $50 \mu \mathrm{g}$ of levonorgestrel is required on a daily basis to suppress ovulation, but an LNG-IUS releases only $20 \mu \mathrm{g}$ of levonorgestrel a day [5]. As the serum level of levonorgestrel varies largely among women; the inhibition of ovulation with an LNG-IUS occurs in very few women. After an LNG-IUS insertion, anovulatory cycles are seen in 5 to $15 \%$ of women and the level of levonorgestrel in the circulation is higher within these cycles. Plasma estradiol (E2) and progesterone measurements are at a similar level to those of women who have normal ovulation [6]. These effects are mostly seen in the first year of usage and in periods when ovulatory cycles occur [7]. However, LNG-IUS is an effective treatment for heavy menstrual bleeding [8-10], changes in bleeding patterns, especially reduction of blood loss, may be a reason to remove LNG-IUS for most women who request only contraception. LNG-IUSs have effects on quality of life depending on culture influences, religious affiliations and expectations of women. In addition, the number of women removing LNG-IUS due to bleeding disturbance or oligo/amenorrhea varies to a large extent depending on the quality of consultation [11].

On the other hand, the use of LNG-IUSs can be associated with development of functional ovarian cysts $[12,13]$. Although, these cysts are asymptomatic, relatively small in size and may show spontaneous resolution [14], they may lead patients to unnecessary apprehension regarding the use of this method of contraception.
The objective of this study was to assess bleeding disturbances and ovarian cysts that may develop in the first year of using an LNG-IUS in Turkish women.

\section{Materials and Methods}

273 healthy parous Turkish women with regular menstrual cycles (bleeding occurred in an interval between 25-32 days and continued not more than 5 days) who were administered LNG-IUS (Mirena',Schering AG, Germany) for contraception in Tepecik Training and Research Hospital, Obstetrics and Gynecology Department were included in the present study. Personal consultation was given to all subjects, who met the contraceptive conformity criteria of the World Health Organization before administering LNG-IUS. All of the subjects were assessed with vaginal ultrasonography (LogiqP5, General Electronic Co.,USA) together with pelvic examination before the process. Any pathologies of the ovaries and uterus, having menstrual bleeding disturbances before LNG-IUS insertion and dislocation of intrauterine device during follow-up were exclusion criterias. The subjects' ages, number of children and miscarriages and their fertility targets were recorded. During the one year follow-up, every month, they were performed vaginal ultrasonography within 5 days of menstrual onset or within 5 days of expected menstrual onset by the same gynecologist. Also, they were questioned monthly about changes in their menstrual

*Corresponding author: Umit Nayki, Yavuz selim Mah. Ersite Asude Yap kooperatifi B blok K:2 D:4 24180, Erzincan, Turkey, Tel: +90446 2122216; Fax: +90 446 2122212; E-mail: drumit75@hotmail.com

Received May 18, 2015; Accepted July 16, 2015; Published July 23, 2015

Citation: Nayki U, Nayki C, Ulug P, Kulhan M, Erdonmez A, et al (2015) Menstrual Bleeding Patterns and Development of Ovarian Cysts in Turkish LevonorgestrelReleasing Intrauterine System Users. J Health Med Informat 6: 194. doi:10.4172/21577420.1000194

Copyright: ( 2015 Nayki U, et al. This is an open-access article distributed under the terms of the Creative Commons Attribution License, which permits unrestricted use, distribution, and reproduction in any medium, provided the original author and source are credited. 
cycles. Each women was asked to record the length of menstrual cycles, days of bleeding and self-assessment of the amount of the menstrual loss. The type of bleeding disturbance they had and in what month of use this occurred, the time of occurrence and diameters of ovarian cysts that were observed with vaginal ultrasonography during the follow-up were all noted.; Oligomenorrhea was defined as the presence of scanty bleeding in an interval longer than 6 weeks; spotting as occasional and unpredictable discharge of small amounts of blood; menorrhagia as heavy and frequent bleeding $[15,16]$. An ovarian cyst was defined as having a mean diameter over $25 \mathrm{~mm}$ [17].

We divided patients into groups according to the existence of oligomenorrhea or not; or development of ovarian cyst or not. Then, according to the beginning time of the complaint, the patients who had oligomenorrhea were divided into three subgroups. Group 1 included the patients who had oligomenorrhea within 3 months after LNG-IUS insertion; group 2 included patients who had oligomenorrhea within 4-6 months after insertion, and group 3 included the patients who had oligomenorrhea within 7-12 months after insertion. Similiarly, the patients who developed ovarian cysts during 1 year follow-up were divided into three subgroups according to the beginning time of this complaint.

Each woman was informed about the study, and provided their written approval. Also, the study was approved by the Ethics Committee of the hospital.

The statistical analysis was performed using the Statistical Package for the Social Sciences version 14 (SPSS Inc., Chicago, IL, USA). Chisquared test was used to analyze the differences within the groups. Pearson's chi-squared test was used to analyze independent nonparametric values. Significance was set at $p<0.05$.

\section{Results}

The socio-demographical characteristics of the subjects were shown in Table 1.

During their one year follow-up, $13.5 \%$ of the subjects ( $n=37)$ were seen to have bleeding disturbances in the form of oligomenorrhea, $5 \%(n=18)$ in the form of menorrhagia and $5 \%(n=18)$ in the form of spotting.

Oligomenorrhea, the most common menstrual disorder in LNGIUS users, was observed in only two (7\%) of the 27 subjects who were older than 45 years. It was seen in 4 (9\%) of the 46 subjects in the $40-44$ age group, in $13(15 \%)$ of the 88 subjects in the $35-39$ age group, in $14(17 \%)$ of the 82 subjects in the $30-34$ age group, in $3(12 \%)$ of the 25 subjects in the 25-29 age group and in one (20\%) of the 5 subjects in the 19-24 age group, respectively (Table 2). There was no significant difference between age and development of oligomenorrhea $(\mathrm{p}=0.699)$. Oligomenorrhea occurred within 4-6 months of LNG-IUS insertion in $70.3 \%$ of the subjects, within the first three months of insertion in $18.9 \%$ of them and within 7-12 months of insertion in $10.8 \%$ of them. We found the difference among these subgroups significant $(\mathrm{p}=0.000)$ (Table 3).

In addition, ovarian cysts were found in $28 \%(n=77)$ of all subjects within a year. Among these patients who developed ovarian cysts during the follow-up, 35\% of them $(n=27)$ had a diameter between 51 and $60 \mathrm{~mm}$. Overall, $21 \%(\mathrm{n}=16)$ of the ovarian cysts had a diameter of $25-30 \mathrm{~mm}, 25 \%(\mathrm{n}=19)$ were $31-40 \mathrm{~mm}, 17 \%(\mathrm{n}=13)$ were $41-50 \mathrm{~mm}$ and $1.3 \%(\mathrm{n}=1)$ were larger than $60 \mathrm{~mm}$, respectively. No ovarian cyst was found in the group below 30 years of age. Ovarian cysts were found in 23 of the 27 subjects above 45 years of age, in 21 of the 46 subjects between 40 and 44 years of age, in 18 of the 88 subjects between 35 and 39 years of age, and in 15 of the 82 subjects between 30 and 34 years of age (Table 2). As the ages of subjects decreased, the percentage of ovarian cysts also decreased and this was statistically significant $(\mathrm{p}=0.000) .57 \%$ of the ovarian cysts occurred within 7-12 months after the administration of LNG-IUSs during one-year follow-up. Overall, $36 \%$ of the ovarian cysts occurred within 4 to 6 months of administering LNG-IUSs and 7\% of them within 3 months. The differences between these three subgroups were also significant $(\mathrm{p}=0.006)$ (Table 3 ).

\section{Discussion}

Women using LNG-IUS experience changes in bleeding patterns such as spotting, menorrhagia and oligomenorrhea. The rate of bleeding disturbance (15-71\%) varied between studies [18-20]. Oligo/ amenorrhea was reported in $15-20 \%$ of the LNG-IUS users within the first year of use and increased to $30-40 \%$ with longer duration of use [15,21]. Besides, Hidalgo and et al. also observed spotting in $25 \%$ of the users at 6 months [15]. Similarly, Suvisaari and Lahteenmaki reported that spotting occurred frequently in the first 4-6 cycles after LNG-IUS insertion. However, after this transition period, regular menstrual cycles started to be seen with a decreasing number of days and amount of bleeding [22]. The present study was consistant with the literature.

There is a growing evidence of women's dissatisfaction with LNGIUS because of a high incidence of adverse effects. Menstruel bleeding disturbance is one of the most important reason for removal of the LNG-IUS [18,23]. Where the LNG-IUS is used as a contraceptive method, reduction of blood loss is mostly considered as an advantage [24], however it may also be a reason for removal [25]. LNG-IUS

\begin{tabular}{|l|lc|}
\hline & $n$ & \\
\hline Age(years) & & 1.8 \\
\hline $19-24$ & 5 & 9.2 \\
\hline $25-29$ & 25 & 30 \\
\hline $30-34$ & 82 & 32.2 \\
\hline $35-39$ & 88 & 16.9 \\
\hline $40-44$ & 46 & 9.9 \\
\hline$\geq 45$ & 27 & 0 \\
\hline The number of the children & & 5.9 \\
\hline 0 & 0 & 77.7 \\
\hline 1 & 16 & 9.1 \\
\hline 2 & 212 & 7.3 \\
3 & 25 & 77.6 \\
$\geq 4$ & 20 & 3 \\
Fertility goals & 212 & 4 \\
No more wish to have a baby & 8 & 15.3 \\
\hline Wish to have a baby in following 2 years & 11 & \\
Wish to have a baby after 2 years & 42 & \\
Uncertain & &
\end{tabular}

Table 1: Socio-demographic characteristics of the patients.

\begin{tabular}{|l|cccc|}
\hline & \multicolumn{2}{|l}{ Oligomenorrhea } & \multicolumn{2}{l|}{$\begin{array}{c}\text { Functional ovarian } \\
\text { Cyst }\end{array}$} \\
\hline Age (years) & $\mathbf{n}$ & $\%$ & $\mathbf{n}$ & $\%$ \\
\hline $19-24$ & 1 & 2.7 & 0 & 0 \\
\hline $25-29$ & 3 & 8.2 & 0 & 0 \\
\hline $30-34$ & 14 & 37.8 & 15 & 18.29 \\
\hline $35-39$ & 13 & 35.1 & 18 & 20.45 \\
\hline $40-44$ & 4 & 10.8 & 21 & 45.65 \\
\hline $45-\uparrow$ & 2 & 5.4 & 23 & 85.18 \\
\hline
\end{tabular}

Table 2: Distribution of oligomenorrhea and ovarian cyst occurance in Turkish LNG-IUS users according to age. 


\begin{tabular}{|l|cccc|}
\hline & \multicolumn{2}{|l}{ Oligomenorrhea } & \multicolumn{2}{c|}{ Functional ovarian } \\
Cyst
\end{tabular}

Table 3: Reconition time of oligomenorrhea and ovarian cysts in Turkish LNGIUS users.

were found to be significantly more likely to discontinue because of oligomenorrhea than nonhormonal intrauterine device users [26]. In a study, it was reported that oligomenorrhea was more likely to be seen at 12 months of insertion in women who used LNG-IUS for contraception than women who used it to manage heavy menstrual bleeding [16].

Use of a LNG-IUS can be associated with the development of functional ovarian cysts [17]. In the present study, we found ovarian cysts in $28 \%$ of all subjects within a year. $57 \%$ of these occurred at $4-6$ months and $36 \%$ at $7-12$ months after insertion. We observed that these cysts were more frequent in older women than in younger ones. Supporting our findings, the incidence of persistent ovarian follicles during LNG-IUS use has been reported in the range of $8 \%-31 \%$ in a study [14]. However, Borgfeldt et al. found ovarian cysts at a rate of $6.6 \%$ in a randomly sampled population of women between 25 and 40 years of age. Also, they stressed that ovarian follicles could rarely reach a diameter of $30 \mathrm{~mm}$ and the upper limit was not known. They observed that $82 \%$ of the cysts disappeared within a period of three months [17]. In a Finnish trial of women referred for hysterectomy or LNG-IUS due to heavy menstrual bleeding, ovarian cysts were more common among women randomized to LNG-IUS compared to hysterectomy: 17.5 vs $3.0 \%$ and 21.5 vs $8.0 \%$ at 6 and 12 months, respectively. They also reported spontaneous resolution in $94.1 \%$ of the cysts. They revealed that the occurrence of cysts did not correlate to the age or the FSH level. However, they found a weak correlation between the occurrence of cysts and irregular bleeding [13]. On the other hand, LNG-IUS use was reported to be associated with the development of ovarian cysts in $40.5 \%$ of premenopausal women at 6 months of insertion [26]. Barbosa et al. reported that LNG-IUSs sometimes inhibited ovulation and the changes in hypothalamic-pituitary- ovarian functions affected follicle development and rupture, and caused the production of new cysts [27]. In an another study, an increase in the "mean arterial pulsatility index", a decrease in serum progesterone level, thinning of the endometrium and ovarian cysts were found in $31 \%$ of the subjects after a three-month treatment with LNG-IUS. All of these cysts disappeared in the fourmonth follow-up period. The mean serum estradiol ratios were found to be higher in the subjects who were found to have ovarian cysts than in those who did not have them. The mean serum levonorgestrel levels also tended to be higher in those subjects who were found to have ovarian cysts [28].

Ovarian cysts are also seen in women using other contraceptive methods. The presence of ovarian cysts and similiarly high spontaneous resolution rates have been documented in both LNG-IUS and progestin-releasing implant users [29,30]. However, cysts were found more frequent in women using LNG-IUS than in women using combined oral contraceptives or no hormonal contraception [17].

The Royal College of Obstetricians and Gynecologists (RCOG) has stated that although there are guidelines about the management of ovarian cysts in postmenopausal women, there is no nationally accepted algorithm about the management of ovarian cysts in premenopausal women. Moreover, there is no consensus about the routine ultrasonographic follow-up of LNG- IUS users, because ovarian cysts will be subject to spontaneous resolution at a high rate. It is not known for certain how long one should wait for the resolution of ovarian cysts and when and how often ultrasonography will be used. This issue was not raised in the past when LNG-IUS use was less common. Today, as the use of LNG-IUSs becomes more widespread, the algorithms related to ovarian cysts and their managements will gain priority [31].

There are some limitations of this study. Firstly, our sample size was small. Secondly, in our study, the evaluation of blood loss was subjective. Also, self-reported bleeding patterns could be biased that women may have been effected by their own ideas or religious affiliations or cultural influences regarding menstrual patterns. Using bleeding charts to investigate the bleeding patterns would have been objective.

Contrary to the studies concerning menstrual disturbance and ovarian cyst related to LNG-IUS in different ethnic populations, data on this topic in Turkish women is insufficient. Our study has some differences from the similar ones in the literature. For example, each ultrasonographic examination was done by the same gynecologist and was timed to a particular menstrual cycle phase. All of these methodological factors are likely to effect the results.

In conclusion, use of LNG-IUS appears to bring about some disturbance in ovarian function, resulting cyst formation and it probably exerts a local effect on endometrium, leading menstrual bleeding disturbances in Turkish women, similar to women from different nations. As Sturridge and Guillebaud stated before, the only undesired non-contraceptive effect of the LNG-IUS is possible development of functional ovarian cysts and the relationship between the level of menstrual bleeding and ovarian function; when we understand these better, we can offer appropriate consultation to women and in this way the acceptability of the method becomes maximum and we can establish continuity in the use of the method" [32].

Conflict of Interest: Umit Nayki, Cenk Nayki, Pasa Ulugi Mehmet Kulhan, Aysegul Erdonmez, Keana Ertopce and Yusuf Yildirim stated no conflict of interest.

\section{References}

1. French R, Van Vliet H, Cowan F, Mansour D, Morris S, et al. (2004) Hormonally impregnated intrauterine systems (IUSs) versus other forms of reversible contraceptives as effective methods of preventing pregnancy. Cochrane Database Syst Rev CD001776.

2. Halmesmäki K, Hurskainen R, Tiitinen A, Teperi J, Grenman S, et al. (2004) A randomized controlled trial of hysterectomy or levonorgestrel-releasing intrauterine system in the treatment of menorrhagia-effect on FSH levels and menopausal symptoms. Hum Reprod 19: 378-382.

3. British -National -Formulary (2007) Intrauterine progestogen-only system. 54 430-431

4. Silverberg SG, Haukkamaa M, Arko H, Nilsson CG, Luukkainen T (1986) Endometrial morphology during long-term use of levonorgestrel-releasing intrauterine devices. Int J Gynecol Pathol 5: 235-241.

5. Luukkainen T, Lahteenmaki P, Toivonen J (1990) Levonorgestrel-releasing intrauterine device. Ann Med 22: 85-90.

6. Xiao BL, Zhou LY, Zhang XL, Jia MC, Luukkainen T, et al. (1990) Pharmacokinetic and pharmacodynamic studies of levonorgestrel-releasing intrauterine device. Contraception 41: 353-362.

7. Nilsson CG, Lahteenmaki PL, Luukkainen T (1984) Ovarian function in amenorrheic and menstruating users of a levonorgestrel-releasing intrauterine device. See comment in PubMed Commons below Fertil Steril 41: 52-55.

8. Gopimohan R, Chandran A, Jacob J, Bhaskar S, Aravindhakshan R, et al. (2015) A clinical study assessing the efficacy of a new variant of the levonorgestrel intrauterine system for abnormal uterine bleeding. Int J Gynaecol Obstet 129: 114-117. 
Citation: Nayki U, Nayki C, Ulug P, Kulhan M, Erdonmez A, et al (2015) Menstrual Bleeding Patterns and Development of Ovarian Cysts in Turkish Levonorgestrel- Releasing Intrauterine System Users. J Health Med Informat 6: 194. doi:10.4172/2157-7420.1000194

9. Lethaby AE, Cooke I, Rees M (2005) Progesterone or progestogen-releasing intrauterine systems for heavy menstrual bleeding. Cochrane Database Syst Rev CD002126.

10. Hurskainen R, Teperi J, Rissanen P, Aalto AM, Grenman S, et al. (2001) Quality of life and cost-effectiveness of levonorgestrel-releasing intrauterine system versus hysterectomy for treatment of menorrhagia: a randomised trial. Lancet 357: 273-277.

11. Ronnerdag $M$, Odlind V (1999) Health effects of long-term use of the intrauterine levonorgestrel-releasing system. A follow-up study over 12 years of continuous use. Acta Obstet Gynecol Scand 78: 716-721.

12. Nahum GG, Kaunitz AM, Rosen K, Schmelter T, Lynen R (2015) Ovarian cysts: presence and persistence with use of a $13.5 \mathrm{mg}$ levonorgestrel-releasing intrauterine system. Contraception 91: 412-417.

13. Inki P, Hurskainen R, Palo P, Ekholm E, Grenman S, et al. (2002) Comparison of ovarian cyst formation in women using the levonorgestrel-releasing intrauterine system vs. hysterectomy. Ultrasound Obstet Gynecol 20: 381-385.

14. Burkman R, Schlesselman JJ, Zieman M (2004) Safety concerns and health benefits associated with oral contraception. Am J Obstet Gynecol 190: S5-22.

15. Hidalgo M, Bahamondes L, Perrotti M, Diaz J, Dantas-Monteiro C, et al. (2002) Bleeding patterns and clinical performance of the levonorgestrel-releasing intrauterine system (Mirena) up to two years. Contraception 65: 129-132.

16. de Jonge ET, Yigit R, Molenberghs G, Straetmans D, Ombelet W (2007) Predictors of oligoamenorrhea at 1-year follow-up in premenopausal women using a levonorgestrel-releasing intrauterine system. Contraception 76: 91-95.

17. Borgfeldt C, Andolf $E$ (1999) Transvaginal sonographic ovarian findings in a random sample of women 25-40 years old. Ultrasound Obstet Gynecol 13: 345-350.

18. Backman T, Huhtala S, Blom T, Luoto R, Rauramo I, et al. (2000) Length of use and symptoms associated with premature removal of the levonorgestre intrauterine system: a nation-wide study of 17,360 users. BJOG 107: 335-339.

19. Halmesmäki K, Hurskainen R, Teperi J, Grenman S, Kivelä A, et al. (2007) The effect of hysterectomy or levonorgestrel-releasing intrauterine system on sexual functioning among women with menorrhagia: a 5-year randomised controlled trial. BJOG 114: 563-568.

20. Hurskainen R, Teperi J, Rissanen P, Aalto AM, Grenman S, et al. (2004) Clinical outcomes and costs with the levonorgestrel-releasing intrauterine system or hysterectomy for treatment of menorrhagia: randomized trial 5-year follow-up. JAMA 291: 1456-1463.
21. Sivin I, Stern J (1994) Health during prolonged use of levonorgestrel 20 micrograms/d and the copper TCu 380Ag intrauterine contraceptive devices: a multicenter study. International Committee for Contraception Research (ICCR). Fertil Steril 61: 70-77.

22. Suvisaari J, Lahteenmaki P (1996) Detailed analysis of menstrual bleeding patterns after postmenstrual and postabortal insertion of a copper IUD or a levonorgestrel-releasing intrauterine system. Contraception 54: 201-208.

23. Backman T, Huhtala S, Blom T, Luoto R, Rauramo I, et al. (2000) Length of use and symptoms associated with premature removal of the levonorgestrel intrauterine system: a nation-wide study of 17,360 users. BJOG 107: 335-339.

24. Baldaszti E, Wimmer-Puchinger B, Löschke K (2003) Acceptability of the longterm contraceptive levonorgestrel-releasing intrauterine system (Mirena): a 3-year follow-up study. Contraception 67: 87-91.

25. Andersson K, Odlind V, Rybo G (1994) Levonorgestrel-releasing and copperreleasing (Nova T) IUDs during five years of use: a randomized comparative trial. Contraception 49: 56-72.

26. Morelli M, Di Cello A, Zullo F (2013) Managing persistent ovarian follicles in premenopausal women fitted with the levonorgestrel-releasing intrauterine system. Int J Gynaecol Obstet 120: 187.

27. Barbosa I, Olsson SE, Odlind V, Goncalves T, Coutinho E (1995) Ovarian function after seven years' use of a levonorgestrel IUD. Adv Contracept 11 85-95.

28. Jarvela I, Tekay A, Jouppila P (1998) The effect of a levonorgestrel-releasing intrauterine system on uterine artery blood flow, hormone concentrations and ovarian cyst formation in fertile women. Hum Reprod 13: 3379-3383.

29. Hidalgo MM, Lisondo C, Juliato CT, Espejo-Arce X, Monteiro I, et al. (2006) Ovarian cysts in users of Implanon and Jadelle subdermal contraceptive implants. Contraception 73: 532-536.

30. Pakarinen PI, Suvisaari J, Luukkainen T, Lähteenmäki P (1997) Intracervica and fundal administration of levonorgestrel for contraception: endometrial thickness, patterns of bleeding, and persisting ovarian follicles. Fertil Steril 68: 59-64.

31. Royal College of Obstetricians and Gynaecologists (RCOG) (2003). Ovarian Cysts in Postmenopausal Women (RCOG Guideline No.34). London, UK RCOG Press.

32. Sturridge F, Guillebaud J (1996) A risk-benefit assessment of the levonorgestrelreleasing intrauterine system. Drug Saf 15: 430-440. 